\title{
Characterization of the postsynaptic protein neurogranin in paired cerebrospinal fluid and plasma samples from Alzheimer's disease patients and healthy controls
}

Hlin Kvartsberg ${ }^{1,2^{*}}$, Erik Portelius ${ }^{1}$, Ulf Andreasson ${ }^{1}$, Gunnar Brinkmalm¹, Konstantin Hellwig ${ }^{3}$, Natalia Lelental ${ }^{3}$, Johannes Kornhuber ${ }^{3}$, Oskar Hanssonn ${ }^{4}$, Lennart Minthonn ${ }^{4}$, Philipp Spitzer ${ }^{3}$, Juan M Maler ${ }^{3}$, Henrik Zetterberg ${ }^{1,5}$, Kaj Blennow ${ }^{1}$ and Piotr Lewczuk ${ }^{3}$

\begin{abstract}
Introduction: Synaptic dysfunction and degeneration are central events in Alzheimer's disease (AD) pathophysiology that are thought to occur early in disease progression. Synaptic pathology may be studied by examining protein biomarkers specific for different synaptic elements. We recently showed that the dendritic protein neurogranin $(\mathrm{Ng})$, including the endogenous $\mathrm{Ng}$ peptide 48 to $76\left(\mathrm{Ng}_{48-76}\right)$, is markedly increased in cerebrospinal fluid (CSF) in AD and that $\mathrm{Ng}_{48-76}$ is the dominant peptide in human brain tissue. The aim of this study was to characterize $\mathrm{Ng}$ in plasma and CSF using mass spectrometry and to investigate the performance of plasma $\mathrm{Ng}$ as an AD biomarker.

Methods: Paired plasma and CSF samples from patients with AD $(n=25)$ and healthy controls $(n=20)$ were analyzed in parallel using an immunoassay developed in-house on the Meso Scale Discovery platform and hybrid immunoaffinity-mass spectrometry (HI-MS). A second plasma material from patients with $A D(n=13)$ and healthy controls $(n=17)$ was also analyzed with HI-MS. High-resolution mass spectrometry was used for identification of endogenous plasma $\mathrm{Ng}$ peptides.
\end{abstract}

Results: $\mathrm{Ng}$ in human plasma is present as several endogenous peptides. Of the 16 endogenous $\mathrm{Ng}$ peptides identified, seven were unique for plasma and not detectable in CSF. However, $\mathrm{Ng}_{48-76}$ was not present in plasma. CSF Ng was significantly increased in AD compared with controls $(P<0.0001)$, whereas the plasma $\mathrm{Ng}$ levels were similar between the groups in both studies. Plasma and CSF Ng levels showed no correlation. CSF Ng was stable during storage at $-20^{\circ} \mathrm{C}$ for up to 2 days, and no de novo generation of peptides were detected.

Conclusions: For the first time, to our knowledge, we have identified several endogenous $\mathrm{Ng}$ peptides in human plasma. In agreement with previous studies, we show that CSF Ng is significantly increased in AD as compared with healthy controls. The origin of $\mathrm{Ng}$ in plasma and its possible use as a biomarker need to be further investigated. The results suggest that CSF Ng, in particular $\mathrm{Ng}_{48-76}$, might reflect the neurodegenerative processes within the brain, indicating a role for $\mathrm{Ng}$ as a potential novel clinical biomarker for synaptic function in AD.

\footnotetext{
* Correspondence: hlin.johansson-schmidt@neuro.gu.se

${ }^{1}$ Department of Psychiatry and Neurochemistry, Institute of Neuroscience and Physiology, The Sahlgrenska Academy, University of Gothenburg, House V3/SU Mölndal, SE-431 80 Mölndal, Sweden

${ }^{2}$ AlzeCure Foundation, Karolinska Institutet Science Park, Hälsovägen 7,

SE-141 57 Huddinge, Sweden

Full list of author information is available at the end of the article
}

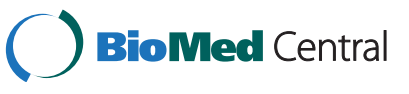

(c) 2015 Kvartsberg et al.; licensee BioMed Central. This is an Open Access article distributed under the terms of the Creative Commons Attribution License (http://creativecommons.org/licenses/by/4.0), which permits unrestricted use, distribution, and reproduction in any medium, provided the original work is properly credited. The Creative Commons Public Domain Dedication waiver (http://creativecommons.org/publicdomain/zero/1.0/) applies to the data made available in this article, unless otherwise stated. 


\section{Introduction}

Alzheimer's disease (AD) is a neurodegenerative disease characterized by neuropathological changes in the brain, including extracellular amyloid- $\beta$ (A $\beta$ ) deposits called plaques as well as neurofibrillary tangles consisting of hyperphosphorylated tau protein (p-tau) [1,2]. Lower cerebrospinal fluid (CSF) levels of the 42-amino acid-long A $\beta$ peptide $A \beta_{1-42}$, reflecting the plaque pathology, together with increased concentrations of total tau ( $\mathrm{t}$-tau) and $\mathrm{p}$-tau, reflecting neurodegeneration and tangle pathology, respectively, are today considered the core CSF biomarkers for AD [3].

A central event in AD pathology is synaptic dysfunction and degeneration [4]. Synaptic loss correlates with cognitive decline and is more associated with the degree of dementia compared to plaques and tangles [5-8], especially within certain areas of the brain, such as the hippocampus $[7,9]$. Furthermore, synaptic loss has been identified as an early event in the disease progression, as well as the underlying cause of the progressive cognitive deterioration as the disease advances [4]. Thus, synaptic markers are promising tools for early AD diagnosis. Moreover, such biomarkers could also be used to monitor disease progression and play an important role in the evaluation of novel disease modifying therapeutics.

Neurogranin $(\mathrm{Ng})$ is a postsynaptic protein with a critical role in long-term potentiation, where it regulates the levels of calmodulin in response to intracellular calcium levels after neuronal excitation [10-12]. In the brain, $\mathrm{Ng}$ is localized to dendritic spines of neurons within associative cortical areas, including the hippocampus, amygdala and cerebral cortex $[11,13]$. Studies on rodents have shown that both the Ng mRNA and total protein levels are age-dependently decreased in several regions of the brain, including the hippocampus [14]. In addition, in situ hybridization studies on the human brain have shown that the Ng mRNA is selectively translocated to dendrites and that such translocation is impaired in the cortex of patients with $\mathrm{AD}[15]$.

Recently, we generated three monoclonal anti-Ng antibodies with epitopes near the C-terminal part of the protein [16]. By immunoprecipitation using the antibodies Ng2 and Ng3, followed by high-resolution mass spectrometry (MS), we identified several endogenous $\mathrm{Ng}$ peptides in both brain tissue and CSF. A third monoclonal antibody, $\mathrm{Ng} 7$, was used as a capturing antibody in an enzyme-linked immunosorbent assay (ELISA) developed in-house for measuring CSF Ng. In three independent cohorts, we showed increased CSF $\mathrm{Ng}$ levels in AD CSF as compared with healthy controls. Using hybrid finity MS (HI-MS), we also showed that the endogenous $\mathrm{Ng}$ peptide 48 to $76\left(\mathrm{Ng}_{48-76}\right)$ was significantly increased in AD CSF as compared with controls [16].
If a synaptic marker reflecting the ongoing synaptic degeneration in the central nervous system (CNS) could be identified in blood or plasma, it would be a very valuable clinical tool because CSF sampling is considered to be a somewhat more invasive procedure. In addition, simple and repeated sampling would also be made possible, allowing for dynamic changes to be measured over time at a regular clinic. Therefore, in this study of paired plasma and CSF samples, we aimed to first characterize $\mathrm{Ng}$ in plasma using MS and then investigate whether plasma Ng is a marker of synaptic degeneration in AD.

Using MS, we show-for the first time, to our knowledge- that $\mathrm{Ng}$ is expressed as a variety of endogenous $\mathrm{Ng}$ peptides in human plasma. Although plasma Ng was not found to differ between $\mathrm{AD}$ patients and healthy controls, we replicated the previous finding of increased CSF Ng in the $\mathrm{AD}$ group using an in-house assay developed on the Meso Scale Discovery (MSD) platform. Finally, we also show that CSF Ng is stable during storage and that no peptides are generated de novo. The endogenous peptide $\mathrm{Ng}_{48-}$ 76, which in our previous study was found to be significantly increased in both patients with $\mathrm{AD}$ and individuals with prodromal $\mathrm{AD}$, was not found in plasma. The findings presented in the present study imply that CSF Ng might reflect the ongoing neurodegenerative processes within the CNS, indicating a role for $\mathrm{Ng}$, and in particular $\mathrm{Ng}_{48-76}$, as a potential novel clinical biomarker for synaptic function in $\mathrm{AD}$.

\section{Methods}

Anonymized plasma samples collected in the routine workflow at the Neurochemistry Laboratory at Sahlgrenska University Hospital, Mölndal, Sweden, were used for method development, as approved by the ethics committee at the University of Gothenburg.

\section{Patients in paired cerebrospinal fluid and plasma study}

The paired CSF and plasma study included 25 AD patients (mean age: $76 \pm 8$ years) and 20 control subjects without dementia (mean age: $54 \pm 14$ years) (see Table 1 for demographics and biomarker characteristics). The $\mathrm{AD}$ group consisted of patients with probable $\mathrm{AD}$ with a high level of evidence of an $\mathrm{AD}$ pathophysiologic process and patients with mild cognitive impairment with a high likelihood of an underlying $\mathrm{AD}$ process. In the rest of this article, this group is called $A D$. The patients were recruited in Erlangen, Germany, and each underwent a thorough clinical investigation, including a medical history as well as a physical, neurological and psychiatric examinations. The diagnosis of $\mathrm{AD}$ was made according to the National Institute of Neurological and Communicative Disorders and StrokeAlzheimer's Disease and Related Disorders association (NINCDS-ADRDA) criteria [17]. No patient with AD had a family history of dementia suggestive of autosomal dominant $\mathrm{AD}$. The control group consisted of patients 
Table 1 Demographic and clinical characteristics of subjects included in the study 1 and $2^{\mathrm{a}}$

\begin{tabular}{|c|c|c|}
\hline & Control & $A D$ \\
\hline $\begin{array}{l}\text { Study } 1 \\
\text { (paired plasma + CSF) }\end{array}$ & $n=20$ & $\mathrm{n}=\mathbf{2 5}$ \\
\hline $\begin{array}{l}\text { Sex, } n \text {, female/male } \\
\text { (\% female) }\end{array}$ & $12 / 8(60)$ & 14/11 (56) \\
\hline Age at $L P, y r$ & 54 (41 to 63$)$ & $76(71 \text { to } 78)^{b}$ \\
\hline $\mathrm{CSF} A \beta_{1-42,} \mathrm{pg} / \mathrm{ml}$ & 1,399 (1189 to 1702$)$ & $709(588 \text { to } 897)^{b}$ \\
\hline $\operatorname{CSF} A \beta_{1-42} / A \beta_{1-40}$ ratio & 0.094 (0.079 to 0.104$)$ & $0.033(0.028 \text { to } 0.042)^{b}$ \\
\hline CSF t-tau, pg/ml & 185 (136 to 254$)$ & $580(425 \text { to } 655)^{b}$ \\
\hline CSF p-tau, pg/ml & 35 (27 to 45$)$ & 89 (78 to 105 to 126$)^{b}$ \\
\hline CSF Ng, pg/ml (MSD) & 291 (251 to 438) & $620(521 \text { to } 818)^{b}$ \\
\hline Plasma Ng, pg/ml (MSD) & $\begin{array}{l}47,451(21,904 \text { to } \\
90,320)\end{array}$ & $\begin{array}{l}36,525(25,324 \text { to } \\
57,715)\end{array}$ \\
\hline Plasma, pg/ml (HI-MS) & $\begin{array}{l}21,698(13,401 \text { to } \\
106,954)\end{array}$ & $\begin{array}{l}25,644(17,262 \text { to } \\
53,900)\end{array}$ \\
\hline Study 2 (plasma) & $\mathrm{n}=17$ & $n=13$ \\
\hline $\begin{array}{l}\text { Sex, } n \text {, female/male } \\
\text { (\% female) }\end{array}$ & 9/17 (53) & 9/13 (69) \\
\hline Age at $L P, y r$ & 58 (53 to 68$)$ & $78(69 \text { to } 80)^{b}$ \\
\hline $\mathrm{CSF} A \beta_{1-42}, \mathrm{pg} / \mathrm{ml}$ & 875 (580 to 940$)$ & $330(268 \text { to } 415)^{b}$ \\
\hline CSF t-tau, pg/ml & 300 (210 to 348$)$ & $690(605 \text { to } 980)^{b}$ \\
\hline CSF p-tau, pg/ml & 48 (40 to 61$)$ & $110(77 \text { to } 160)^{b}$ \\
\hline
\end{tabular}

${ }^{a} A \beta$, Amyloid- $\beta$; AD, Alzheimer's disease; CSF, Cerebrospinal fluid; HI-MS, Hybrid immunoaffinity-mass spectrometry; LP, lumbar puncture; MSD, Meso Scale Discovery; $\mathrm{Ng}$, Neurogranin; $\mathrm{p}$-tau, Phosphorylated tau; $\mathrm{t}$-tau, Total tau. The values presented are median (interquartile range). ${ }^{\mathrm{b}} P<0.001$ vs. controls.

with other neuropsychiatric conditions without dementia. The clinical diagnoses (including neuroimaging and neuropsychology) were combined with the results of the following CSF biomarkers: $A \beta_{1-42}, A \beta_{1-40}$ (to calculate the $A \beta_{42 / 40}$ concentration ratio), $t$-tau and $p$-tau181. The subjects were included in the study only if the clinical, neuroimaging and neuropsychological diagnoses were in accordance with the neurochemical findings as described elsewhere [18]. There were no patients included in the study with a completely negative AD biomarker pattern. Control subjects had all biomarkers within normal ranges. CSF t-tau, p-tau, $A \beta_{1-40}$ and $A \beta_{1-42}$ concentrations were determined using established ELISA methods as described elsewhere [18]. All analyses were performed at the Universitätsklinikum Erlangen. The study was conducted according to the provisions of the Declaration of Helsinki. All subjects gave their written informed consent for the use of their clinical data for research purposes, as approved by the ethics committee of the Universitätsklinikum Erlangen.

\section{Patients and plasma samples included in the verification study}

Plasma samples were collected from 13 patients with $\mathrm{AD}$ (mean age: $78 \pm 7$ years) and 17 individuals without dementia (controls; mean age: $58 \pm 9$ years) at the Memory Clinic, Skåne University Hospital, Sweden (see Table 1 for full biomarker characteristics and demographics). The individuals underwent brain imaging, routine laboratory testing and neurological, psychiatric and cognitive examinations. Patients diagnosed with AD fulfilled the dementia criteria of the Diagnostic and Statistical Manual of Mental Disorders, Third Edition, Revision [19], and the criteria for probable AD as defined by NINCDS-ADRDA [17]. The control individuals without dementia experienced subjective cognitive symptoms at baseline, but thorough clinical investigation as well as clinical follow-up revealed that the patients were not affected by a dementia disorder or a neurological disease. CSF t-tau, p-tau and $\mathrm{A} \beta_{1-42}$ concentrations were determined using established ELISA methods as described elsewhere [16]. All analyses were performed at the Clinical Neurochemistry Laboratory at the Sahlgrenska University Hospital, Mölndal, Sweden. All individuals gave their informed consent to participate in research before their samples were stored in a biobank. A passive consent procedure was then used whereby consent for retrospective use of banked samples and basic data was assumed if individuals did not actively retract permission, as instructed in local press advertisements. This study procedure was approved by the local ethics committee at Lund University, Sweden.

\section{Meso Scale Discovery neurogranin assay}

The monoclonal mouse antibody $\mathrm{Ng} 7$, with an epitope including amino acids 52 to 65 [16], was used as a capturing antibody and was coated on QUICKPLEX 96-well plates (Meso Scale Discovery (MSD), Rockville, MD, USA) at a final concentration of $2.0 \mu \mathrm{g} / \mathrm{ml}(40 \mu \mathrm{l} /$ well $)$ in phosphate-buffered saline (PBS), followed by incubation overnight at room temperature (RT). Before being coated with the capturing antibody, the plates were washed once with $150 \mu \mathrm{l}$ of PBS. After the plates were washed with $300 \mu \mathrm{l}$ of PBS containing 0.05\% Tween 20 (PBS-Tween) four times for 30 seconds each time, the remaining protein-binding sites were blocked with 5\% MSD Blocker A solution (150 $\mu \mathrm{l} /$ well; Meso Scale Discovery) for 1 hour at RT and subsequently washed again with $300 \mu \mathrm{l}$ of PBS-Tween four times for 30 seconds each time. Then the full-length $\mathrm{Ng}$ calibrators with concentrations ranging between 31.3 and 4,000 pg/ml (1:2 dilution; CSF samples) or 31.3 to $23,000 \mathrm{pg} / \mathrm{ml}$ (1:3 dilution; plasma samples), blanks and samples $(50 \mu \mathrm{l} /$ well $)$ were incubated in duplicate together with the detecting antibody, polyclonal Ng anti-rabbit antibody (ab23570; Upstate Biotechnology, Lake Placid, NY, USA) diluted 1:20,000 in $0.1 \%$ bovine serum albumin (BSA) in PBS-Tween overnight at RT (50 $\mu \mathrm{l} /$ well). Plasma samples were diluted 1:40 in PBS. After washing four times for 30 seconds each time in PBS-Tween, a MSD SULFO-TAG goat anti-rabbit 
antibody (25 $\mu \mathrm{l} /$ well; Meso Scale Discovery), concentration $0.5 \mu \mathrm{g} / \mathrm{ml}$ diluted in $0.1 \%$ BSA in PBS-Tween, was added and incubated for 2 hours at RT while being shaken at $700 \mathrm{rpm}$. After washing with $300 \mu \mathrm{l}$ of PBS-Tween four times for 30 seconds each time, $150 \mu$ l of $2 \times$ MSD Read Buffer T with surfactant (Meso Scale Discovery) were used for immediate reading with a QUICKPLEX SQ 120 reader (Meso Scale Discovery). A fitted four-parameter logistic model with relative weighting $\left(1 / y^{2}\right)$ was used as the calibration curve, and the blank was included as zero concentration of $\mathrm{Ng}$. All samples were analyzed without knowledge of clinical diagnosis.

\section{Immunoprecipitation/matrix-assisted laser desorption/ ionization time-of-flight/time-of-flight analysis}

To minimize nonspecific binding of other proteins during the immunoprecipitation, all plasma samples were pretreated twice with $20 \mu \mathrm{l}$ of Novex Dynabeads Protein G (Life Technologies, Carlsbad, CA, USA) per milliliter of plasma and incubated for 1 hour at RT before the beads were magnetically removed as described previously, with some modifications [20]. HI-MS analysis of Ng peptides was performed as described elsewhere [16]. In brief, $4 \mu \mathrm{g}$ of the monoclonal anti-Ng antibodies $\mathrm{Ng} 2$ and $\mathrm{Ng} 3$ were separately added to $25 \mu \mathrm{l}$ of Dynabeads M-280 sheep anti-mouse immunoglobulin G (Life Technologies) and cross-linked as previously described [21]. Beads coated with $\mathrm{Ng} 2$ and $\mathrm{Ng} 3$ were used for immunoprecipitation of plasma to which $n$-octyl- $\beta$-D-glucopyranoside (10\%, end concentration 0.1\%; Fluka Chemie, Buchs, Switzerland) had been added. The beads and sample were transferred to a KingFisher magnetic particle processor (polypropylene tubes; Thermo Scientific, Waltham, MA, USA) for automatic washing and elution of the $\mathrm{Ng}$ peptides and protein. Eluted $\mathrm{Ng}$ was collected and dried in a vacuum centrifuge and redissolved in $5 \mu \mathrm{l}$ of $0.1 \%$ formic acid (FA) in $20 \%$ acetonitrile and subsequently analyzed using an ultrafleXtreme matrixassisted laser desorption/ionization (MALDI) time-of-flight/ time-of-flight (TOF/TOF) MS (Bruker Daltonics, Bremen, Germany). All solvents used were of high-performance liquid chromatography (HPLC) quality.

In both the paired cohort and validation study where MALDI-TOF/TOF MS was used, the custom Ng peptide RKKIKSGERGRKGPGPGGPGGAGVARGGAGGGP (corresponding to $\mathrm{Ng}_{43-75}$ ), with glycine labeled with double ${ }^{13} \mathrm{C}$ (theoretical molecular mass: 3,011 Da; CASLO, Lyngby, Denmark), was added to the plasma prior to sample preparation and was used as an internal standard. Samples were analyzed blinded (that is, without knowledge of clinical diagnosis).

\section{High-resolution tandem mass spectrometry}

The identities of the $\mathrm{Ng}$ peptides were confirmed using a top-down approach as previously described [22], but with updated instrumentation. Briefly, analysis was performed using nanoflow liquid chromatography (Dionex UltiMate 3000; Thermo Scientific) coupled to an electrospray ionization Q Exactive Hybrid Quadrupole Orbitrap tandem mass spectrometer (Thermo Scientific). An Acclaim PepMap 100 C8 trap column (length: $20 \mathrm{~mm}$; inner diameter: $75 \mu \mathrm{m}$; particle size: $3 \mu \mathrm{m}$; pore size: $100 \AA$ (Thermo Scientific)) was used for online desalting, and a reversed-phase Acclaim PepMap rapid separation liquid chromatography column (length: $500 \mathrm{~mm}$, inner diameter: $75 \mu \mathrm{m}$; particle size: $2 \mu \mathrm{m}$; pore size: $100 \AA$ (Thermo Scientific)) was used for high-resolution separation. Mobile phases were $0.1 \%$ aqueous FA (v/v) (A) and $0.1 \%$ FA in $84 \%$ acetonitrile in water (v/v) (B). The separation was performed at a flow rate of $150 \mathrm{nl} / \mathrm{min}$ by applying a linear gradient of $3 \%$ to $40 \%$ B for 50 minutes. A column oven was used and set to $40^{\circ} \mathrm{C}$. All solvents used were of HPLC quality. The $\mathrm{Q}$ Exactive system was used in positive ion mode to acquire full-scan spectra in the 300 to 1,200 mass-to-charge $(\mathrm{m} / \mathrm{z})$ ratio range at a resolution setting of 70,000. Subsequent tandem mass spectra (MS/MS) were produced using the higher-energy collisional dissociation fragmentation cell and acquired at the same resolution setting. An inclusion list was employed to ensure that we obtained MS/MS data of the compounds of interest. Mass spectral raw files were then charge-deconvoluted by using Mascot Distiller software (Matrix Science, Boston, MA, USA) and subsequently submitted to a Mascot database search (Matrix Science).

\section{Degradation of neurogranin in plasma and cerebrospinal fluid at room temperature}

Plasma and CSF samples were depleted of native $\mathrm{Ng}$ by three consecutive immunoprecipitations before full-length recombinant $\mathrm{Ng}(1,000 \mathrm{pg} / \mathrm{ml})$ was added to the samples, followed by 24-hour incubation at RT. After the incubation, samples were analyzed by HI-MS to screen for degradation products from the full-length $\mathrm{Ng}$ protein in the form of newly formed $\mathrm{Ng}$ peptides.

\section{Cerebrospinal fluid neurogranin storage stability assessment}

Pooled CSF samples with or without a stabilizing agent (sodium azide at a final concentration of $0.1 \%$ in samples), were kept at $\mathrm{RT}, 4^{\circ} \mathrm{C}$ or $-20^{\circ} \mathrm{C}$ for 1 to 7 days before they were placed in long-term storage at $-80^{\circ} \mathrm{C}$ pending analysis. As a reference sample, a freshly prepared aliquot, with or without stabilizer, was stored at $-80^{\circ} \mathrm{C}$ on the day of the preparation (that is, day 0 ). All other samples were normalized against the $\mathrm{Ng}$ content of the respective reference sample for either group. $\mathrm{Ng}$ content was analyzed by MSD. 


\section{Statistical analysis}

For statistical analysis, Prism 6 for Windows software (GraphPad Software, La Jolla, CA, USA) was used. Because biomarker values were skewed, nonparametric tests were used. Differences between groups were assessed using the Mann-Whitney $U$ test, and significance was determined at $P<0.05$. Correlations were determined using Spearman's correlation.

\section{Results}

\section{Characterization of plasma neurogranin}

Plasma Ng was characterized using MALDI-TOF/TOF and high-resolution MS/MS. Several short C-terminal peptides were repeatedly detected by MALDI-TOF/TOF, and 16 of these were independently verified and identified by high-resolution MS/MS (Figure $1 \mathrm{~A}$ and Table 2). Of these, seven had not previously been detected in brain tissue or CSF [16]. A summary of all $\mathrm{Ng}$ peptides that have been identified using MS in plasma, CSF and brain tissue can be found in Additional file 1: Table S1. A cluster of peaks at the $\mathrm{m} / \mathrm{z}$ ratio corresponding roughly to full-length $\mathrm{Ng}$ (theoretical mass: 7,618 $\mathrm{Da}$ ) was detected (Figure 1B), indicating that the protein most likely is subjected to several posttranslational modifications; however, these have yet to be identified.

\section{Clinical validation of paired plasma and cerebrospinal fluid samples}

Paired plasma and CSF samples from patients with AD and controls were analyzed for $\mathrm{Ng}$ levels to investigate the potential of plasma $\mathrm{Ng}$ as a novel biomarker. Plasma samples were analyzed in parallel by using an MSD platform assay and HI-MS targeting both the shorter endogenous peptides and full-length $\mathrm{Ng}$. Using HI-MS,

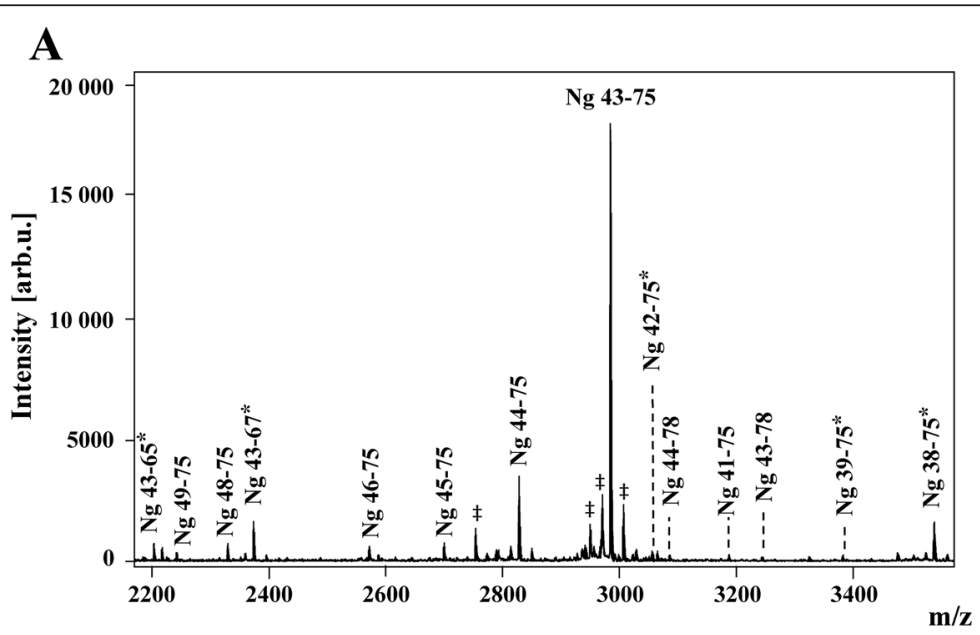

B

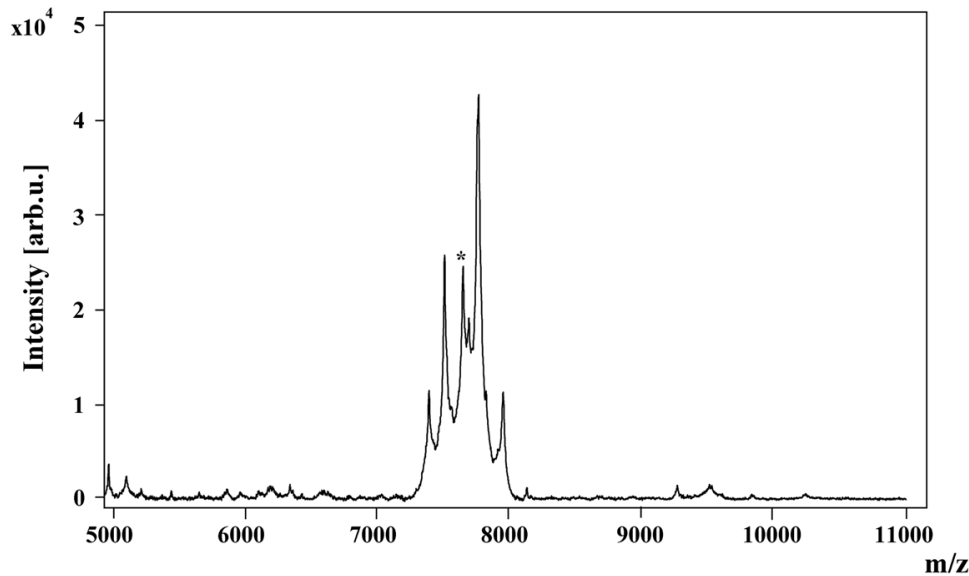

Figure 1 Hybrid immunoaffinity-mass spectrometry characterization of plasma neurogranin. (A) Hybrid immunoaffinity-mass spectrometry analysis of human plasma repeatedly detected several short C-terminal peptides. *Peptides found only in plasma and not in cerebrospinal fluid or brain tissue. ${ }^{\ddagger}$ Nonspecific binding of other plasma proteins to magnetic beads. (B) A cluster of peaks roughly corresponding to the mass of full-length neurogranin $(\mathrm{Ng})$ is present in plasma. *Peak corresponding to the theoretical mass of full-length $\mathrm{Ng}(7,618 \mathrm{Da})$. $\mathrm{m} / \mathrm{z}$, Mass-to-charge ratio. 
Table 2 Identified plasma neurogranin peptides by high-resolution mass spectrometry ${ }^{a}$

\begin{tabular}{|c|c|c|c|c|c|}
\hline Calculated mass (Da) & Theoretical mass $(\mathrm{Da})$ & Deviation (ppm) & Confirmed sequence & Number of $y$-ions & Number of b-ions \\
\hline $1,899.98$ & $1,899.98$ & -1.3 & 52 to $75^{\mathrm{b}}$ & 1 & 11 \\
\hline 2,203.24 & $2,203.24$ & 1.7 & 43 to $65^{\mathrm{b}}$ & 1 & 14 \\
\hline $2,217.24$ & $2,217.25$ & -1.8 & 44 to $67^{b}$ & 2 & 8 \\
\hline $2,242.14$ & $2,242.14$ & -0.1 & 49 to 75 & 5 & 12 \\
\hline $2,329.18$ & 2,329.17 & 1.0 & 48 to 75 & 10 & 20 \\
\hline $2,373.34$ & $2,373.35$ & -1.0 & 43 to $67^{b}$ & 0 & 6 \\
\hline $2,570.36$ & $2,570.35$ & 1.8 & 46 to 75 & 10 & 17 \\
\hline $2,698.45$ & $2,698.45$ & 0.1 & 45 to 75 & 12 & 19 \\
\hline $2,826.54$ & $2,826.54$ & -2.4 & 44 to 75 & 19 & 21 \\
\hline $2,982.64$ & $2,982.64$ & -1.7 & 43 to 75 & 21 & 8 \\
\hline $3,053.69$ & $3,053.68$ & 2.9 & 42 to $75^{b}$ & 18 & 6 \\
\hline $3,085.61$ & $3,085.62$ & -4.3 & 44 to 78 & 6 & 12 \\
\hline $3,184.73$ & $3,184.72$ & 2.7 & 41 to 75 & 14 & 4 \\
\hline $3,241.72$ & $3,241.73$ & -1.6 & 43 to 78 & 19 & 13 \\
\hline $3,378.81$ & $3,378.80$ & 1.8 & 39 to $75^{\mathrm{b}}$ & 8 & 2 \\
\hline $3,534.91$ & $3,534.90$ & 1.7 & 38 to $75^{\mathrm{b}}$ & 11 & 10 \\
\hline
\end{tabular}

${ }^{a}$ Mass deviation is displayed in parts per million (ppm). ${ }^{b}$ Peptides found only in plasma and not in cerebrospinal fluid or brain tissue.

several plasma $\mathrm{Ng}$ peptides were reliably detected and quantified, but none were found to differ significantly between the groups. Concentrations of the most abundant plasma $\mathrm{Ng}$ peptide, $\mathrm{Ng}_{43-75}$, which was present in all samples, are displayed in Figure 2A. This finding was replicated by HI-MS analysis in a second independent plasma material, where, once again, none of the peptides differed between patients with $\mathrm{AD}$ and healthy controls. Concentrations of $\mathrm{Ng}_{43-75}$ obtained in the validation study are displayed in Figure 2B. The peaks at the mass range of full-length $\mathrm{Ng}$ (Figure 1B) were also investigated, but no significant difference was obtained between patients with $\mathrm{AD}$ and healthy controls (data not shown). In agreement with this, MSD analysis of plasma Ng did not reveal any quantitative differences between the groups (Figure 2C).

In contrast, MSD analysis of the CSF samples showed a marked increase of $\mathrm{Ng}$ in patients with $\mathrm{AD}$ $(P<0.0001)$ (Figure 2D). As the control group was significantly younger than the AD group in both studies (see Table 1), we also tested for a correlation between CSF Ng and age, but no such association was found in the paired cohort (AD group: $P=0.667, r_{\mathrm{s}}=-0.1$; control group: $\left.P=0.11, r_{\mathrm{s}}=-0.37\right)$ or in the validation study (AD group: $P=0.258, r_{\mathrm{s}}=0.34$; control group: $P$ $\left.=0.77, r_{\mathrm{s}}=-0.08\right)$. No correlation between CSF and plasma $\mathrm{Ng}$ was found in the paired cohort $(P=0.83$, $\left.r_{\mathrm{s}}=0.0334\right)$. Owing to the large CSF volume needed for HI-MS analysis $(1 \mathrm{ml})$, the CSF samples were analyzed only by MSD.

\section{Neurogranin storage stability and degradation in} cerebrospinal fluid and plasma

With the purpose of investigating the stability of CSF $\mathrm{Ng}$ during storage, CSF was kept at RT, $4^{\circ} \mathrm{C}$ or $-20^{\circ} \mathrm{C}$ with or without the addition of a stabilizer for between 1 and 7 days before it was stored at $-80^{\circ} \mathrm{C}$ pending analysis. The samples were analyzed using the MSD Ng assay, and all values were normalized against a reference sample, which was stored at $-80^{\circ} \mathrm{C}$ on the day of preparation. The CSF Ng levels were stable at RT for 2 days, after which the concentration dropped to around 70\% compared with the day of preparation. Samples kept at either $4^{\circ} \mathrm{C}$ or $-20^{\circ} \mathrm{C}$ were both stable for all time points investigated (Figure 3A). Similar results were obtained when a stabilizing agent was added (Figure 3B).

To address the question whether any degradation of $\mathrm{Ng}$ occurs in CSF and plasma, CSF and plasma samples that had been depleted of all native $\mathrm{Ng}$ by immunoprecipitation using $\mathrm{Ng} 2$ and $\mathrm{Ng} 3$ were spiked with full-length $\mathrm{Ng}$ $(1,000 \mathrm{pg} / \mathrm{ml})$ and incubated at RT for 24 hours. The samples were then analyzed for newly generated $\mathrm{Ng}$ peptides using HI-MS. In CSF, no Ng peptides generated de novo could be detected in the spiked samples after the incubation (data not shown). In contrast, $14 \mathrm{Ng}$ peptides were detected in the spiked plasma samples, indicating that $\mathrm{Ng}$ is degraded in plasma (Additional file 2: Table S2).

\section{Discussion}

In this study, we characterized the $\mathrm{Ng}$ content in plasma and investigated the potential of plasma $\mathrm{Ng}$ as a biomarker for $\mathrm{AD}$. We also addressed the stability of CSF $\mathrm{Ng}$ during 
A

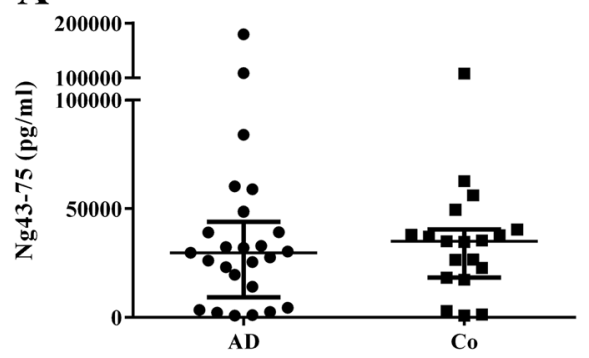

C

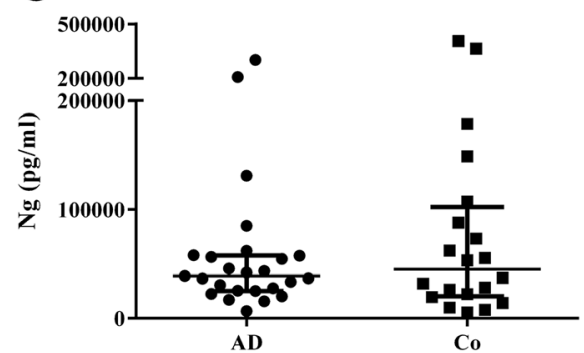

B

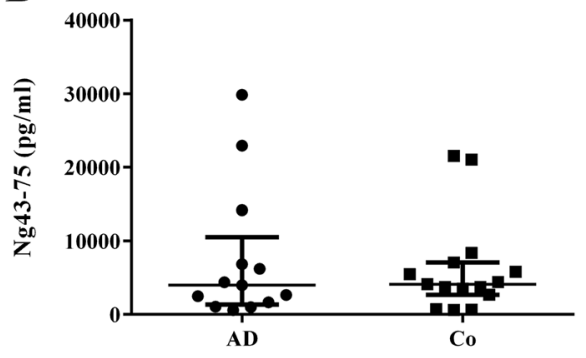

D

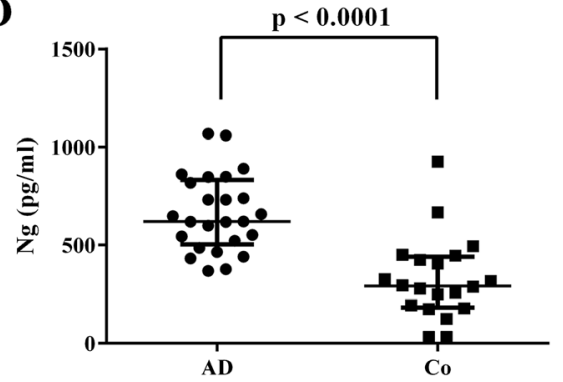

Figure 2 Scatterplots displaying the results from hybrid immunoaffinity-mass spectrometry and Meso Scale Discovery analysis of plasma and cerebrospinal fluid samples. (A) Scatterplot of plasma concentrations of the most abundant neurogranin ( $\mathrm{Ng}$ ) peptide 43 to 75 ( $\mathrm{Ng}_{43-75}$ ), in samples from the paired cohort obtained by hybrid immunoaffinity-mass spectrometry (HI-MS). (B) Scatterplot of plasma Ng $43-75$ concentrations in samples from the verification study obtained by HI-MS. (C) Scatterplot of plasma Ng levels obtained by Meso Scale Discovery (MSD) in samples from the paired cohort. (D) Scatterplot of cerebrospinal fluid $\mathrm{Ng}$ levels obtained by MSD. The data presented are medians and interquartile ranges. AD, Alzheimer's disease; Co, Control.

storage and investigated any potential degradation of $\mathrm{Ng}$ in both CSF and plasma.

In total, we identified 16 endogenous $\mathrm{Ng}$ peptides in plasma. We also show that full-length $\mathrm{Ng}$ most likely is present, but mostly in posttranslationally modified forms. Of the endogenous plasma peptides, seven had not been detected previously in either brain tissue or CSF [16]. Thus, they seem to be plasma-specific. As we have now performed HI-MS analysis of $\mathrm{Ng}$ peptides in more than 75 plasma samples in total and the plasma-specific peptides have been present in all of these, we can conclude that these are consistently found in plasma and are thus most likely not caused by the preanalytical handling,

In a previous study, we showed increased CSF Ng levels in AD using ELISA [16]. In the same study, using MS, we also found that, of the endogenous $\mathrm{Ng}$ peptides examined, $\mathrm{Ng}_{48-76}$ showed the most pronounced increase in AD CSF compared with controls. Importantly, $\mathrm{Ng}_{48-76}$ was also found to be the dominant peptide in AD brain tissue [16], but this peptide was not found in plasma (Table 2). These data suggest that this particular peptide most likely is brain-specific. Furthermore, there are also peptides that are unique for plasma as well as for CSF and brain tissue (Additional file 1: Table S1). Thus, Ng peptides detected in CSF may specifically reflect ongoing neurodegenerative processes within the brain and are most likely not influenced by $\mathrm{Ng}$ peptides produced in the periphery, indicating that they may have valid clinical relevance. Further supporting CSF $\mathrm{Ng}$ as an AD marker are the discoveries that the plasma $\mathrm{Ng}$ levels did not differ between $\mathrm{AD}$ and controls (Figure 2A, B and C) and that there was a lack of correlation between CSF and plasma Ng content.

In a series of experiments designed to test the stability of $\mathrm{Ng}$ in plasma, we show that recombinant full-length protein incubated in plasma, depleted of native $\mathrm{Ng}$, is metabolized into a variety of fragments (Additional file 2: Table S2), probably by some of the proteases present in plasma. Five of the detected degradation fragments most likely correspond to endogenous peptides that were identified in native plasma samples, and, in addition to those, we also detected a number of peaks that most likely correspond to other $\mathrm{Ng}$ peptides that have not been seen in their native counterparts (Additional file 2: Table S2). Also, four of the $\mathrm{Ng}$ peptides found only in plasma were not generated after incubation of full-length $\mathrm{Ng}$ in $\mathrm{Ng}$-depleted plasma, thus indicating that they are not an artefact of sample handling. This indicates that there are several enzymes present in plasma that are capable of cleaving $\mathrm{Ng}$. As the peptide patterns of native plasma $\mathrm{Ng}$ and degraded full-length $\mathrm{Ng}$ differ, this might point toward differences regarding the enzymes in freeze-thawed plasma samples and enzymes in plasma in vivo with regard to activity and/or specificity. 

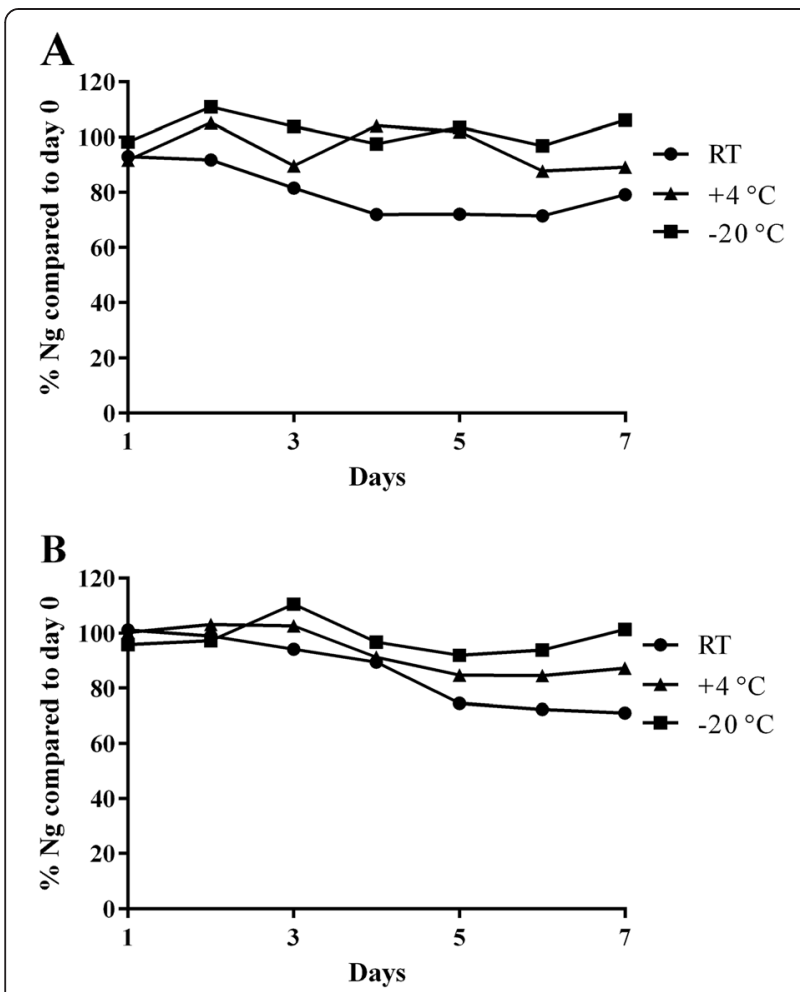

Figure 3 Analysis of cerebrospinal fluid neurogranin storage stability. Normalized cerebrospinal fluid neurogranin $(\mathrm{Ng})$ concentrations in samples without $(\mathbf{A})$ or with $(\mathbf{B})$ the addition of a stabilizing agent. Samples were kept at room temperature (RT), $4^{\circ} \mathrm{C}$ or $-20^{\circ} \mathrm{C}$ for between 1 and 7 days before transfer to storage at $-80^{\circ} \mathrm{C}$ pending analysis. Samples were normalized to day 0, with or without stabilizer.

These differences could be due to a number of different factors, such as $\mathrm{pH}$ or storage stability. However, a characterization of the active enzymes in plasma after $-80^{\circ} \mathrm{C}$ storage that are capable of cleaving full-length $\mathrm{Ng}$ to generate the peptides observed in such samples is beyond the scope of this article.

$\mathrm{Ng}_{48-76}$ was neither naturally occurring (Table 2) nor generated after incubation of full-length $\mathrm{Ng}$ in the plasma samples investigated (Additional file 2: Table S2). Therefore, it is unlikely that this specific peptide is produced in the periphery. These findings indicate that the enzyme responsible for the formation of $\mathrm{Ng}_{48-76}$ is present only in the brain or at least is not active in either CSF or plasma. This hypothesis is further supported by the fact that, though there are three $\mathrm{Ng}$ peptides in CSF that end with amino acid 76 (Additional file 1: Table S1), neither these endogenous peptides (Table 2) nor fragments generated from recombinant full-length protein (Additional file 2: Table S2) were found in plasma. The enzymes responsible for the different cleavages of $\mathrm{Ng}$ remains to be identified.

Compared with CSF, plasma $\mathrm{Ng}$ concentration in paired samples was around 100 times higher (Figure 2C and D).
Studies have shown that $\mathrm{Ng}$ is expressed in the periphery in the spleen, bone marrow, platelets and lung tissue [11], which may contribute to the high concentration in plasma.

Limitations of both studies are their small sample size and that healthy control subjects were significantly younger than the AD patient groups $(P<0.001)$ (Table 1$)$. However, considering that no difference in plasma $\mathrm{Ng}$ was found between the groups in either cohort and that increased CSF $\mathrm{Ng}$ in $\mathrm{AD}$ has been shown before in age-matched groups [16], we believe that the age difference between the groups did not affect the results of this study. Also, we did not find any correlation between age and $\mathrm{Ng}$ concentration in either plasma or CSF.

\section{Conclusions}

The present study shows that $\mathrm{Ng}$ is present in plasma at high concentrations, both as posttranslationally modified full-length protein and as a number of endogenous peptides. The previously reported difference in $\mathrm{Ng}$ levels in CSF between controls and AD patients is a consistent finding that is not reflected in the plasma. The most important discoveries are that there is no degradation of full-length $\mathrm{Ng}$ or de novo formation of peptides in CSF and that CSF $\mathrm{Ng}$ is stable for storage at $-20^{\circ} \mathrm{C}$, as well as that there are no native plasma $\mathrm{Ng}$ peptides ending with amino acid 76. This suggests that CSF Ng, especially $\mathrm{Ng}_{48-76}$, might reflect ongoing neurodegenerative processes within the brain, indicating a role for $\mathrm{Ng}$ as a potential novel clinical biomarker for synaptic function in AD.

\section{Additional files}

Additional 1: Table S1. Summary of all Ng peptides identified by MS/ MS in human brain tissue, CSF and plasma. Microsoft Excel 97-2003 worksheet (.xls). A complete list of all endogenous $\mathrm{Ng}$ peptides identified by MS/MS in human brain tissue, CSF and plasma.

Additional 2: Table S2. Newly formed Ng peptides in plasma incubated with recombinant full-length $\mathrm{Ng}$. Microsoft Excel 97-2003 worksheet (.xls). Plasma samples were depleted of native $\mathrm{Ng}$ by three consecutive immunoprecipitations before full-length recombinant $\mathrm{Ng}(1,000 \mathrm{pg} / \mathrm{ml})$ was added to samples, followed by 24-hour incubation at RT. After the incubation, the samples were analyzed by HI-MS to screen for newly formed $\mathrm{Ng}$ peptides.

\section{Abbreviations}

A $\beta$ : Amyloid- $\beta$; AD: Alzheimer's disease; BSA: Bovine serum albumin; CNS: Central nervous system; CSF: Cerebrospinal fluid; ELISA: Enzyme-linked immunosorbent assay; FA: Formic acid; HI-MS: Hybrid immunoaffinity-mass spectrometry; HPLC: High-performance liquid chromatography;

MALDI: Matrix-assisted laser desorption/ionization; MS: Mass spectrometry; MS/MS: Tandem mass spectrometry; $\mathrm{m} / \mathrm{z}$ : Mass-to-charge ratio;

Ng: Neurogranin; NINCDS-ADRDA: National Institute of Neurological and Communicative Disorders and Stroke/Alzheimer's Disease and Related Disorders Association; PBS: Phosphate-buffered saline; ppm: Parts per million; p-tau: Phosphorylated tau; RT: Room temperature; TOF/TOF: Time-of-flight/ time-of-flight; t-tau: Total tau. 


\section{Competing interests}

$\mathrm{PL}$ received consultation and lecture honoraria from Innogenetics, IBL International, AJ Roboscreen, Beckman Coulter and Roche and holds the position of visiting professor at the Medical University of Białystok, Białystok, Poland. HK, EP, UA, GB, KH, NL, JK, OH, LM, JMM, PS, HZ and KB declare that they have no competing interests.

\section{Authors' contributions}

HK developed the HI-MS and MSD methods, acquired MS and MSD data, analyzed and interpreted data and drafted the manuscript. EP developed the HI-MS method, planned the experimental design and analyzed and interpreted data. UA developed the MSD method and analyzed and interpreted data. GB acquired Q Exactive MS data and analyzed and interpreted data. $\mathrm{KH}$ was involved in MSD data collection and analyzed and interpreted data. NL, JK, JMM and PS were responsible for subjects in the clinical study and analyzed and interpreted data. $\mathrm{OH}$ and LM were responsible for subjects in the validation study, analyzed and interpreted data. $\mathrm{HZ}$ analyzed and interpreted data. KB designed the production of anti-Ng antibodies and analyzed and interpreted data. PL planned the experimental design and analyzed and interpreted data. All authors agree with the presented findings and read and approved the final manuscript.

\section{Acknowledgments}

This study was supported by a generous private donation by Peter Thelin Stockholm, Sweden; the Swedish Research Council (project 14002, K201063P-21562-01-4, K2011-61X-20401-05-6), the Knut and Alice Wallenberg Foundation, Stiftelsen för Gamla Tjänarinnor, Magnus Bergvalls Stiftelse, Gun och Bertil Stohnes Stiftelse, the Swedish Brain Foundation, the Alzheimer Foundation of Sweden, the Dementia Association of Sweden, the European Union Joint Programme-Neurodegenerative Disease Research (JPND) Project BIOMARKAPD, the Swedish Brain Power consortium and the Torsten Söderberg Foundation at the Royal Swedish Academy of Sciences. This study was also supported by the German Bundesministerium für Bildung und Forschung (grant 01ED1203D) within the BIOMARKAPD Project of the JPND.

\section{Author details}

${ }^{1}$ Department of Psychiatry and Neurochemistry, Institute of Neuroscience and Physiology, The Sahlgrenska Academy, University of Gothenburg, House V3/SU Mölndal, SE-431 80 Mölndal, Sweden. ${ }^{2}$ AlzeCure Foundation, Karolinska Institutet Science Park, Hälsovägen 7, SE-141 57 Huddinge, Sweden. ${ }^{3}$ Department of Psychiatry and Psychotherapy, Universitätsklinikum Erlangen and Friedrich-Alexander-Universität Erlangen-Nürnberg, Schwabachanlage 6, 91054 Erlangen, Germany. ${ }^{4}$ Department of Clinical Sciences Malmö, Memory Clinic, Clinical Memory Research Unit, Faculty of Medicine, Lund University, Malmö, Klinikgatan 22, SE-222 42 Lund, Sweden. ${ }^{5}$ Department of Molecular Neuroscience, UCL Institute of Neurology, Queen Square 588, WC1N 3BG London, UK.

Received: 28 January 2015 Accepted: 24 March 2015

Published online: 01 July 2015

\section{References}

1. Blennow K, de Leon MJ, Zetterberg H. Alzheimer's disease. Lancet. 2006;368:387-403.

2. Lewczuk P, Kornhuber J. Neurochemical dementia diagnostics in Alzheimer's disease: where are we now and where are we going? Expert Rev Proteomics. 2011:8:447-58

3. Blennow K, Hampel H, Weiner M, Zetterberg H. Cerebrospinal fluid and plasma biomarkers in Alzheimer disease. Nat Rev Neurol. 2010;6:131-44.

4. DeKosky S, Scheff S. Synapse loss in frontal cortex biopsies in Alzheimer's disease: correlation with cognitive severity. Ann Neurol. 1990;27:457-64.

5. Davies CA, Mann DM, Sumpter PQ, Yates PO. A quantitative morphometric analysis of the neuronal and synaptic content of the frontal and temporal cortex in patients with Alzheimer's disease. J Neurol Sci. 1987;78:151-64.

6. Masliah E, Mallory M, Alford M, DeTeresa R, Hansen LA, McKeel Jr DW, et al. Altered expression of synaptic proteins occurs early during progression of Alzheimer's disease. Neurology. 2001;56:127-9.

7. Scheff SW, Price DA, Schmitt FA, DeKosky ST, Mufson EJ. Synaptic alterations in CA1 in mild Alzheimer disease and mild cognitive impairment. Neurology. 2007:68:1501-8.

8. Sze Cl, Troncoso JC, Kawas C, Mouton P, Price DL, Martin LJ. Loss of the presynaptic vesicle protein synaptophysin in hippocampus correlates with cognitive decline in Alzheimer disease. J Neuropathol Exp Neurol. 1997;56:933-44.

9. Scheff SW, Price DA, Schmitt FA, Mufson EJ. Hippocampal synaptic loss in early Alzheimer's disease and mild cognitive impairment. Neurobiol Aging. 2006;27:1372-84

10. Baudier J, Deloulme JC, Van Dorsselaer A, Black D, Matthes HWD. Purification and characterization of a brain-specific protein kinase $C$ substrate, neurogranin (p17): identification of a consensus amino acid sequence between neurogranin and neuromodulin (GAP43) that corresponds to the protein kinase C phosphorylation site and the calmodulin-binding domain. J Biol Chem. 1991;266:229-37.

11. Díez-Guerra F. Neurogranin, a link between calcium/calmodulin and protein kinase C signaling in synaptic plasticity. IUBMB Life. 2010;62:597-606.

12. Xia Z, Storm D. The role of calmodulin as a signal integrator for synaptic plasticity. Nat Rev Neurosci. 2005:6:267-76.

13. Bogdanovic N, Davidsson P, Gottfries J, Volkman I, Winblad B, Blennow K. Regional and cellular distribution of synaptic proteins in the normal human brain. Brain Aging. 2002;2:18-30.

14. Mons N, Enderlin V, Jaffard R, Hiqueret P. Selective age-related changes in the PKC-sensitive, calmodulin-binding protein, neurogranin, in the mouse brain. J Neurochem. 2001;79:859-67.

15. Chang JW, Schumacher E, Coulter 2nd PM, Vinters HV, Watson JB. Dendritic translocation of RC3/neurogranin mRNA in normal aging, Alzheimer disease and fronto-temporal dementia. J Neuropathol Exp Neurol. 1997:56:1105-18.

16. Kvartsberg H, Duits FH, Ingelsson M, Andreasen N, Öhrfelt A, Andersson K, et al. Cerebrospinal fluid levels of the synaptic protein neurogranin correlates with cognitive decline in prodromal Alzheimer's disease. Alzheimers Dement. In press. doi: 10.1016/j.jalz.2014.10.009.

17. McKhann G, Drachman D, Folstein M, Katzman R, Price D, Stadlan EM. Clinical diagnosis of Alzheimer's disease: report of the NINCDS-ADRDA Work Group under the auspices of Department of Health and Human Services Task Force on Alzheimer's Disease. Neurology. 1984;34:939-44.

18. Lewczuk P, Zimmermann R, Wiltfang J, Kornhuber J. Neurochemical dementia diagnostics: a simple algorithm for interpretation of the CSF biomarkers. J Neural Transm. 2009:116:1163-7.

19. American Psychiatric Association. Diagnostic and statistical manual of mental disorders. 3rd ed. rev. Washington, DC: American Psychiatric Association; 1987;133-55.

20. Pannee J, Törnqvist U, Westerlund A, Ingelsson M, Lannfelt L, Brinkmalm G, et al. The amyloid- $\beta$ degradation pattern in plasma-A possible tool for clinical trials in Alzheimer's disease. Neurosci Lett. 2014;573:7-12.

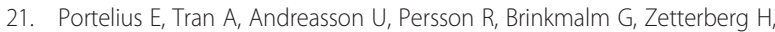
et al. Characterization of amyloid $\beta$ peptides in cerebrospinal fluid by an automated immunoprecipitation procedure followed by mass spectrometry. J Proteome Res. 2007:6:4433-9.

22. Brinkmalm G, Portelius E, Öhrfelt A, Mattsson N, Persson R, Gustavsson MK et al. An online nano-LC-ESI-FTICR-MS method for comprehensive characterization of endogenous fragments from amyloid $\beta$ and amyloid precursor protein in human and cat cerebrospinal fluid. J Mass Spectrom. 2012:47:591-603.

\section{Submit your next manuscript to BioMed Central and take full advantage of:}

- Convenient online submission

- Thorough peer review

- No space constraints or color figure charges

- Immediate publication on acceptance

- Inclusion in PubMed, CAS, Scopus and Google Scholar

- Research which is freely available for redistribution 